\title{
La deformación del lenguaje
}

\section{The deformation of language}

\author{
MARTÍNEZ-MARTÍNEZ, Malinali Xochiquetzal†* \& GARCÍA-RODRÍGUEZ, Juan Carlos
}

Universidad Tecnológica del Norte de Aguascalientes, México.

ID $1^{\mathrm{er}}$ Autor: Malinali Xochiquetzal, Martínez-Martínez / ORC ID: 0000-0002-4111-5950

ID $1{ }^{\mathrm{er}}$ Coautor: Juan Carlos, García-Rodríguez / ORC ID: 0000-0002-3602-7809

DOI: $10.35429 / J O C S .2020 .23 .7 .1 .12$

Recibido 10 de Julio, 2020; Aceptado 30 de Diciembre, 2020

\section{Resumen}

El presente artículo tiene como finalidad realizar un análisis sobre los elementos detonantes en el proceso de deformación y desarrollo de vicios en el lenguaje. Determinar la influencia de los teléfonos inteligentes, las redes sociales y el uso de extranjerismos en la transformación del mismo. El análisis toma importancia por ser parte de los factores que merman el desarrollo de un lenguaje asertivo entre los jóvenes que actualmente están en preparación profesional. Esta investigación se realiza a partir de una observación directa de estudios de caso con la finalidad de analizar las redes sociales de un grupo de personas (voluntarias) para evaluar sus procesos comunicativos, el desarrollo de vicios del lenguaje o generación de faltas ortográficas. Además, de la aplicación una encuesta para evaluar el comportamiento de las personas frente a los elementos que se consideran detonantes para el problema. La principal contribución de la investigación, es el acercamiento que se tiene al análisis de los factores que detonan la deformación del lenguaje y el uso incorrecto del mismo, lo que permite la generación de bases sobre las cuales trabajar futuras investigaciones, para la corrección de las problemáticas actuales generadas en la ortografía a raíz de esta, y que permita ampliar el conocimiento sobre futuras estrategias de acción.

\begin{abstract}
The purpose of this article is to carry out an analysis of the triggering elements in the process of deformation and development of vices in language. Determine the influence of smartphones, social networks and the use of foreign words in its transformation. The analysis is important because it is part of the factors that reduce the development of an assertive language among young people who are currently in professional training. This research is carried out from a direct observation of case studies in order to analyze the social networks of a group of people (volunteers) to evaluate their communication processes, the development of language vices or the generation of spelling mistakes. In addition, the application of a survey to evaluate the behavior of people in the face of the elements that are considered triggers for the problem. The main contribution of the research is the approach taken to the analysis of the factors that trigger the deformation of language and its incorrect use, which allows the generation of bases on which to work future research, for the correction of the current problems generated in spelling as a result of this, and that allows to expand the knowledge about future action strategies.
\end{abstract}

Warp, Influence, Language

Deformación, Influencia, Lenguaje Citación: MARTÍNEZ-MARTÍNEZ, Malinali Xochiquetzal \& GARCÍA-RODRÍGUEZ, Juan Carlos. La deformación del
lenguaje. Revista de Sociología Contemporánea. 2020.7-23:1-12. lenguaje. Revista de Sociología Contemporánea. 2020. 7-23:1-12.

\footnotetext{
* Correspondencia del Autor (correo electrónico: malinali.martinez@utna.edu.mx)

$\dagger$ Investigador contribuyendo como primer autor.
} 


\section{Introducción}

Es claro que el lenguaje es inherente al hombre y a su desarrollo cultural, social y profesional, pues es la principal herramienta para el desarrollo de sus procesos comunicativos. Por lo que el presente proyecto investigativo, tiene como finalidad, el análisis de deformación o transformación que ha sufrido el mismo, en uso de los jóvenes y la influencia que han tenido las redes sociales y el internet sobre éste.

La comunicación se basa principalmente en dos vertientes, verbal (oral y escrita) y no verbal (visual, kinestésica, uso de simbologías, paralenguaje, proxemia, háptica...). Analizar y mantener interés en la forma en que los jóvenes hacen uso de ella, para comunicarse efectivamente, siempre será relevante, si se pretende desarrollar estrategias de estudio y técnicas de comunicación directa con ellos.

El análisis se enfocará directamente en conocer la postura que estos tienen sobre el uso de las herramientas tecnológicas y la importancia que tienen estas, tanto en su desarrollo diario, así como las herramientas de uso común, a través de una observación directa en perfiles de redes sociales, y una encuesta entre estudiantes de la Universidad Tecnológica del Norte de Aguascalientes.

La transformación que ha sufrido el uso que dan al lenguaje los jóvenes, ha dejado como consecuencia cambios drásticos en la correcta escritura, y en el crecimiento tanto de vicios del lenguaje como en excesivas faltas ortográficas, además de la inclusión de extranjerismos y la sustitución palabras por imágenes, para la expresión en redes sociales y en su vida diaria.

Con el fin de indagar sobre el tema y contar con antecedentes teóricos al respecto, se desarrolla un marco de referencia, que dará paso a la generación de un proceso investigativo basado en la generación de una metodología aplicada durante la investigación, para la exposición de los resultados y conclusiones al respecto.

\section{Antecedentes}

El lenguaje es connatural al desarrollo humano, como una forma de expresión en sus procesos comunicativos, para la transmisión de pensamientos, sentimientos y emociones, por lo que la evolución del hombre y su adaptación al cambio en los diferentes contextos de que forma parte, incluye también la adaptación de su lenguaje (que se ha visto transformado a través de los siglos con la propia transformación del hombre) a través de la implicación de nuevos elementos que le faciliten la expresión asertiva de sus ideas, lo cual puede afectar positiva o negativamente de manera directa en la ortografía, y el uso formal del lenguaje.

El uso de la tecnología genera una notable influencia en el desarrollo, uso y costumbres del ser humano, a lo largo de la historia, el sistema educativo se ha visto influenciado positiva y negativamente por la evolución propia.

En el caso particular del lenguaje, resulta importante el análisis de los factores que influyen en el mal uso del mismo y en el desarrollo de vicios que provocan la deformación del mismo.

\section{Hipótesis}

El uso de los teléfonos inteligentes, las redes sociales y los lenguajes extranjeros, principalmente el inglés, deforman nuestro lenguaje y son un detonante para el mal uso de la ortografía y la generación de vicios del lenguaje.

\section{Objetivos}

El objetivo general de esta investigación es:

Analizar los detonantes en el proceso de deformación y desarrollo de vicios en el lenguaje.

Los objetivos específicos son:

- Analizar los elementos que influyen en el proceso de deformación del lenguaje.

- Determinar la influencia de los teléfonos inteligentes, las redes sociales y el uso de extranjerismos en la deformación del lenguaje. 


\section{Marco de Referencia}

La lengua sufre cambios y transformaciones a la par de los procesos de evolución del ser humano, es cambiante y mutable a las necesidades de la sociedad. Respecto al uso de la tecnología en los procesos de comunicación, a todos nos ha pasado que tenemos que escribir un texto, queremos contar una historia o compartir información importante y no hay espacio suficiente para ahondar en detalles. El mensaje tiene que ser breve y concreto; además, dado nuestro ritmo tan acelerado de vida, el tiempo ya tampoco es suficiente para transmitir la información completa. Por lo que tratamos de sintetizar el mensaje lo más que se pueda, y eso incluye no sólo el fondo, sino también la forma, es decir, la estructura que damos al mensaje para que éste sea más corto.

Con la entrada de las nuevas tecnologías en nuestra sociedad, se han desarrollado, a la vez, distintos tipos de discurso que se han amoldado a estas situaciones. Se ha generado un "consenso" para estipular un estilo lingüístico en SMS, correos electrónicos, chats, comentarios en la red o redes sociales. En el caso de las redes sociales, se ha debatido mucho el estilo coloquial que adquiere el lenguaje, un fenómeno lógico si pensamos en el carácter de inmediatez que adquiere este medio.

Dicha deformación no se limita a las redes sociales; de hecho, éstas no son la raíz del problema. Este fenómeno inició con los mensajes de texto SMS, que en 150 caracteres aprox. (incluyendo signos de puntuación y espacios) obligaban a reducir la información sin perder el núcleo del mensaje, el texto se reducía, ya que afectaba a la economía de las personas, porque al pasarse de caracteres ya se cobraban dos o tres mensajes, por eso empezaron a buscar formas de sintetizar para cuidar economía. Lo que nos llevó a poner mensajes sin mucho sentido, olvidando o dejando de lado la sintaxis; lo que poco a poco se volvió una costumbre y se expandió a otros medios. Como el correo electrónico, que, aunque tiene espacio ilimitado de texto, siguió con esa tendencia de reducir los mensajes a su mínima expresión para ahorrar tiempo y energía en transmitir la información.
En nuestro país, específicamente, existe también la influencia constante que recibimos de nuestros vecinos del norte. Con la llegada del Internet, también nos volvimos susceptibles a recibir la influencia del lenguaje escrito en inglés, esto es, palabras sin acentos, un solo signo de admiración o interrogación, etc., y lo aplicamos a nuestros mensajes escritos diarios (mensajes SMS, correos electrónicos, chat, redes sociales, etc.). Esto no significa que se satanice el aprendizaje de otro idioma, sino la aplicación de sus reglas y/o excepciones al nuestro.

Esta situación ha crecido de forma exponencial, pues actualmente, se ha disminuido el índice de edad en que los niños o adolescentes tienen acceso a los celulares y las redes sociales, sobre todo en la generación de jóvenes que a partir de los 12 o 13 años. Esto debe prender focos de alarma, ya que, de seguir así, esta tendencia afectará el aspecto educativo significativamente, pues los estudiantes aplicarán este lenguaje deformado a todos los campos de su vida y no aprenderán a seguir reglas para escribir correctamente, y más adelante será mucho más complicado corregir el mismo. Como dijo Mario Vargas Llosa en relación a las redes sociales: "el internet ha acabado con la gramática, ha liquidado la gramática. De modo que se vive una especie de barbarie sintáctica... Si escribes así, es que hablas así; si hablas así, es que piensas así, y si piensas así."

"Esta particular forma de transmisión de
información se identifica como la
«comunicación del milenio» y su
característica principal debe ser la rapidez,
porque vivimos en un mundo con prisa y que
no puede detenerse; pero poner una coma y
escribir -acer en lugar de - hacer, no nos
quitará el día entero, más bien limpia la
impresión que damos al mundo entero.
Nuestro idioma tiene reglas y debemos
respetar, y no por eso estaremos menos a la
moda, sólo demostraremos nuestra cultura"
(Vire, 2012).

Los cambios de ortografía más importantes son los siguientes: palabras sin acentos, omisión de signos de puntuación (comas, puntos, signos de admiración e interrogación) que muchas veces hacen que el mensaje pierda sentido, y cambios de letras (sobre todo con la letra "q" que cambian por "k", por ejemplo "k", "pk” “aunk", "kiero”, etc.). 
Para los expertos el uso de este tipo de abreviaturas, omisión de tildes y signos de puntuación, ha degenerado el idioma español en algo ininteligible, excepto para las personas que lo usan y que a la larga se han habituado en ellas, lo malo que estas personas son los estudiantes, y preocupante es que se habitúan a esta propuesta. (TICONA, 2017)

Las redes sociales se están volviendo cada vez más y más visuales. Ejemplos como que el éxito de una publicación en Facebook radica en la imagen, y que este éxito se multiplica hasta un $180 \%$ frente a sí publicamos texto, nos da que pensar... ¿Una imagen vale más que mil palabras en redes sociales? ¡Pues sí! Tanto es así que redes sociales como Pinterest e Instagram están teniendo un crecimiento brutal, desbancando a redes sociales como Facebook en su crecimiento en tan poco tiempo. Las imágenes tienen una capacidad inmediata de impactar al usuario. Son más fáciles de leer, compartir y, sobre todo, de jugar con nuestras emociones de forma más rápida y efectiva que un texto, ya que su capacidad emocional es bastante alta.

Según datos del 2015 de la empresa Swyft Media, que se dedica a la creación de teclados virtuales, cada día se envían 6.000 millones de emojis. Teniendo en cuenta que se intercambian 45.000 millones de mensajes a diario, equivale a uno de cada siete mensajes. Agnese Sampietro, doctora en Linguística por la Universidad de Valencia y autora de una tesis sobre el uso, la difusión y el impacto de los emojis, en la que analizó mensajes de WhatsApp de 120 personas, señala que "el $8 \%$ de los datos de esos mensajes son emoticonos, y están presentes sobre todo en conversaciones de carácter informal".

Los emoticonos entran para enfatizar la parte expresiva del lenguaje supliendo los rasgos extralingüísticos y paralingüísticos. A través de ellos se comunica al receptor reacciones que sería imposible expresar en el medio virtual: risa, llanto, duda, complicidad, entre otras. (TICONA, 2017)
Ahora bien, ¿los emojis sustituyen palabras y empobrecen el lenguaje (más allá de sustituir palabras como "adiós" o "besos")? "No empobrecen, sino que permiten aportar información emocional", comenta Eulalia Hernández Encuentra, profesora de la Universitat Oberta de Catalunya y directora del grupo de investigación PSiNET (Psicología, Salud y Red). Cuando hablamos cara a cara, damos color emocional a nuestra conversación con gestos, miradas, cierto tono de voz, lo que se sustituirá con el uso de los emojis en el lenguaje escrito. Sin embargo, muchos opinan que los emoticonos sustituyen el lenguaje y, por tanto, lo empobrecen.

El uso de imágenes animadas (formato .GIF), también ha recobrado vida gracias a su inclusión en los servicios de chat y mensajería instantánea de los dispositivos móviles y aplicaciones web. La palabra escrita tiene menos importancia gracias a la facilidad de inclusión de las imágenes animadas que cautivan y captan la atención de los usuarios que contemplan sus repeticiones y que además contienen siempre un mensaje simbólico de la vida cotidiana en un tono cómico e irónico para representar distintas situaciones fácilmente interpretables por el receptor basadas en elementos de la cultura popular. Lo cual viene a reforzar la idea de la transformación de los mensajes de texto, por mensajes a través de imágenes.

Actualmente el GIF es el principal instrumento de comunicación en la cultura digital debido a la conjunción de sus facilidades y características, las cuales generan la versatilidad del mismo y su carácter omnipresente.

Los GIFs son un lenguaje visual en sí mismo y un vocabulario emotivo creado por la cultura. Este formato al estar orientado a la comunidad, la cual puede hacer uso de su creación y distribución, genera una gran diferencia de significación con las otras maneras de comunicación no verbal (emoticones) en la mensajería instantánea. Esto es porque las comunidades interpretan el mensaje del GIF dentro de su cultura, a partir de sus propias convenciones y creencias. Debido a la ausencia de expresiones físicas y/o emocionales en las conversaciones de chat, surge la presencia del GIF animado como un signo que las sustituya. (Tello, 2018). 
El lenguaje evoluciona constantemente debido a las variaciones que la sociedad manifiesta, y hoy con las redes sociales es aún más notorio. Por eso la Real Academia de la Lengua Española (RAE) y otras organizaciones del lenguaje incorporan y adecúan términos. Un ejemplo de esto son las palabras tuitear, blogger, chatear, además de antitaurino, beatlemanía, brunch y otras que son o están en proceso de ser parte del diccionario oficial.

Algunos autores afirman que esta escritura es una nueva forma de expresión de los jóvenes quienes pretenden mostrar originalidad y rebeldía en estos espacios informales, que son aceptados y entendibles en sus círculos virtuales. Sin embargo, la constante escritura errónea puede confundir y hacer creer que determinados términos están escritos de forma correcta por la repetición de su uso. En vista de esto, hace varios años se creó el término hoygan, en vez de oigan, refiriéndose a las personas que tenían muy mala ortografía y poca cortesía (Linde, 2012); lo que mostraba una protesta para que los cibernautas caigan en cuenta de su falencia ortográfica en las redes. Tanta es la influencia y la deformación que sufre la lengua que la RAE, se encuentra constantemente activa en redes sociales, sobre todo twitter, donde responde y adapta términos coloquiales al uso común.

Durante el 2019, México alcanzó los 80.6 millones de internautas y 86.5 millones de usuarios de comunicaciones móviles, de los que 95.3 por ciento usan Smartphone, según la Encuesta Nacional sobre Disponibilidad y Uso de Tecnologías de la Información en los Hogares 2019 (Endutih 2019).

Si bien en nuestro país ya hay 80.6 millones de usuarios de Internet y 86.5 millones de consumidores de telefonía celular, también es cierto que en las zonas urbanas el promedio de usuarios conectados es de 76.6 por ciento y en las rurales sólo 47.7 por ciento. Lo anterior implicó un aumento ya que mientras que en el 2017 en las zonas urbanas el promedio de conectados mayores a 6 años de edad fue de 71.2 por ciento, en el 2019 aumentó a 76.6 por ciento y en las rurales de 39.2 a $47.7 \%$.
Una encuesta realizada en mayo de 2019 reveló que Facebook es la red social con el mayor porcentaje de usuarios en México. Un 99\% de los usuarios de redes sociales encuestados dijo tener acceso a Facebook. WhatsApp fue la segunda plataforma más usada por los mexicanos, obteniendo un $93 \%$ de los encuestados. En tercer lugar, se ubicó YouTube, con un $82 \%$. En ésta se destacó que el uso de redes sociales en México se ha incrementado en un $9 \%$ durante los últimos 12 meses, con lo que ha llegado a los 83 millones de usuarios.

Para algunos lingüistas, la deformación de las palabras es un avance inevitable para enriquecer el idioma. Para otros, la falta de respeto por la ortografía y la supuesta precarización del lenguaje son cosas del mundo moderno.

\section{Metodología}

Para el desarrollo de la investigación se realizó, en primer lugar, una observación directa a partir de estudios de caso, esto con la finalidad de analizar las redes sociales de un grupo de personas (voluntarias) para evaluar sus procesos comunicativos, el desarrollo de vicios o generación de faltas ortográficas.

Además, se aplicó una encuesta constituida por 15 preguntas cortas de opción múltiple para evaluar el comportamiento de las personas frente a los elementos que se consideran detonantes en la deformación del lenguaje. Las preguntas de la encuesta se muestran a continuación, cabe hacer mención que esta encuesta fue un instrumento auto administrado a través de Google Forms.

1. ¿Con qué regularidad mandas mensajes de texto?

Diario una o dos veces por semana dos o tres veces por mes casi nunca.

2. ¿Acostumbras acortar palabras al escribir los mensajes?

Sí No. Si tu respuesta es Sí, contesta la pregunta tres, si tu respuesta es No, responde la pregunta cuatro.

3. Menciona cinco palabras que acortas comúnmente. 
4. Menciona cinco palabras que identificas que otras personas acortan comúnmente.

5. ¿Cuál es la razón por la que comúnmente se acortan las palabras?

Para ahorrar tiempo

Para ahorrar espacio dentro del texto (menos caracteres)

Me da flojera escribir mucho

Otro: menciona la razón

6. ¿Eres consciente cuando no sabes cómo se escribe correctamente una palabra?

Sí No

7. ¿Qué haces cuando te das cuenta que no sabes cómo se escribe correctamente una palabra?

Buscas en internet como se escribe correctamente.

Le preguntas a alguien como se escribe.

No le das importancia a la situación y dejas el mensaje así, lo importante es que se entienda lo que pretendes decir.

8. ¿Alguna vez has escrito mal una palabra a propósito, por seguir una moda o una tendencia?

Si No. Si tu respuesta es Sí, contesta la pregunta 9, si la respuesta es No, responde la pregunta 10

9. Menciona cinco palabras, que escribes mal por seguir la moda

10. Menciona cinco palabras, que observas que los demás escriben mal por seguir la moda.

11. ¿Cuál es la razón por la que usas imágenes dentro de tus textos escritos?

\section{Moda}

Se ven bonitos o graciosos o siento

Me ayudan a expresar mejor lo que quiero
Otro: especifica la razón

12. ¿Cuál de las siguientes imágenes utilizas con mayor frecuencia para comunicarte en tus redes sociales?

Emoji Sticker Gift Meme

13. ¿Haces uso frecuente de palabras en otro idioma para establecer tus procesos de comunicación?

Sí No

14. ¿Cuáles palabras pertenecientes a otro idioma usas o has visto que los demás usen? Menciona cinco.

15. ¿Consideras que el uso de las redes sociales influye en tu capacidad de comunicarte con otros?

\section{Sí No}

\section{Resultados}

En primer lugar, se enlistan los hallazgos encontrados en el análisis de casos de observación.

En un primer caso, se muestra una conversación basada en emoticonos y sticker, el poco texto que acompaña a la interacción entre las personas involucradas, hace referencia a alabar a quien generó la publicación, se puede observar que se carece de acentuación en las palabras y de signos exclamativos, tanto como de comas y puntos. Se pueden observar comentarios, que carecen de texto, y se limitan exclusivamente al uso de imágenes.

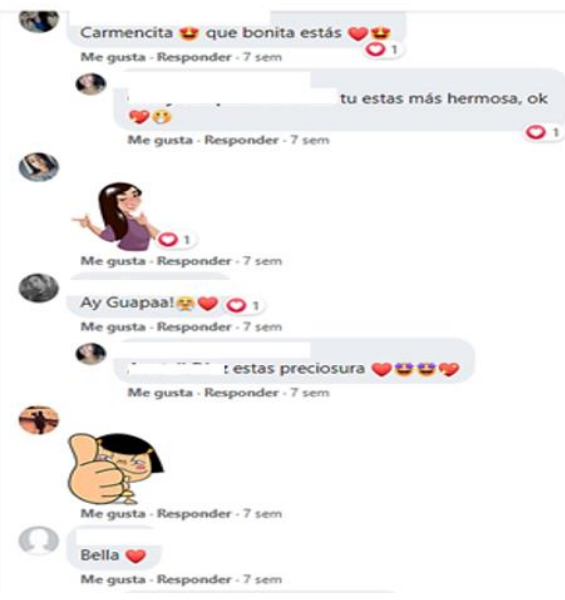

Figura 1 Ejemplo de conversación en redes sociales 
La siguiente captura, es una serie de comentarios generados a raíz de una publicación de un video, como se puede observar, solo hay un comentario escrito, que es justamente de la persona que lo publicó, lo cual indica que tal vez no sabe usar a detalle.

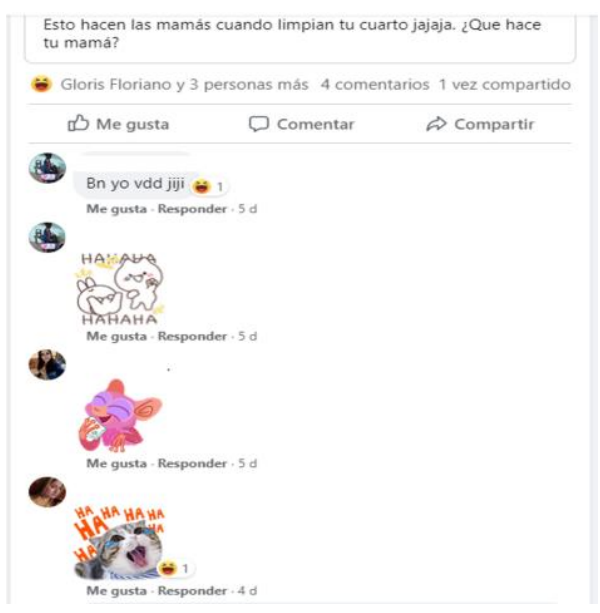

Figura 2 Segundo ejemplo de conversación en redes sociales

Se conserva la forma de expresión a través de imágenes, y la falta de texto significativo entre la interacción de las personas, se observa también la falta de acentuación enfática. Otro punto importante es la diversidad de imágenes que se encuentran en las plataformas digitales para una misma expresión, lo cual abre más oportunidades de expresión a través de ellas y deja de lado la escritura. Los elementos visuales están sustituyendo la generación de textos.

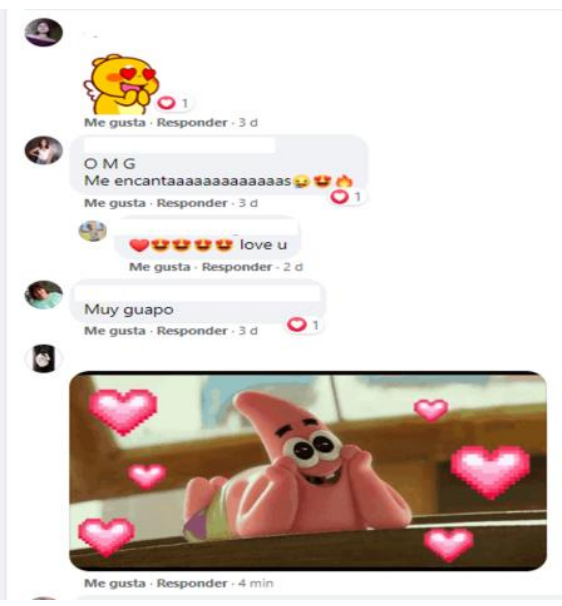

Figura 3 Tercer ejemplo de conversación en redes sociales
En este caso se observa la diversidad de símbolos visuales para la expresión, emoticonos, gifts y sticker forman parte de la diversidad visual que predomina en el uso de las redes sociales como una forma segura de transmitir la expresión de sentimientos o emociones, en el proceso de interacción social. Otro elemento a considerar dentro del ejemplo, es la deformación de las palabras a través del agregado exagerado de letras, como una forma de expresión emocional, con lo cual se suprime y se sustituye el uso de signos exclamativos $(i$ ? y $i$ !).

El último punto observable dentro del ejemplo, que forma parte importante del presente análisis, es la inclusión del uso de palabras pertenecientes a otro idioma (inglés) como parte de las formas comunes de expresión, las cuales se van mexicanizando y adaptando al vocabulario utilizado por los jóvenes, la cual también sufre deformaciones a la expresión formal usada en su idioma de procedencia (el cambio de "I love you" por "love u").

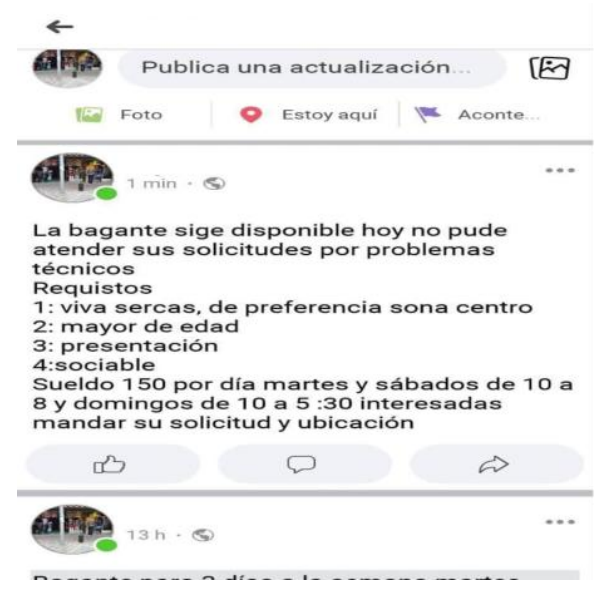

Figura 4 Cuarto ejemplo de conversación en redes sociales

En el último caso se observa una deformación grave en el lenguaje, que se podría considerar como una muestra clara de la problemática actual existente en la deformación del lenguaje y el grave problema de la ortografía, existente entre jóvenes, ya que aunque en esta ocasión no se hace uso de emoticonos, gifts o algún otro elemento visual, es posible observar en un pequeño texto, errores en prácticamente el $50 \%$ del mismo. 
Se observa que la persona que publica, tiene problemas con la dicción de algunas palabras, y eso afecta directamente a la forma en que las escribe, además de problemas frecuentes en el uso equivoco de letras como la b o v, la c, s o z y la falta de la u cuando se trata del uso de la g o la q.

En lo relacionado con la encuesta aplicada, los resultados obtenidos se muestran en seguida:

En la primera pregunta: ¿Con qué regularidad mandas mensajes de texto? Las respuestas fueron:

\section{¿Con qué regularidad mandas mensajes de} texto?

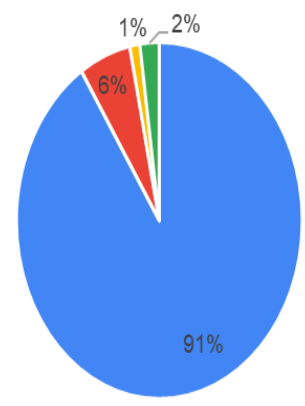

- Diario

Una o dos veces por

semana

- Dos o tres veces por mes

- Casi nunca.

Gráfico 1 ¿Con qué regularidad mandas mensajes de texto Fuente: Elaboración propia

En el gráfico se puede observar la tendencia actual de utilizar los distintos medios de comunicación (redes sociales, utilidades de mensajería o sms de celulares) para establecer contacto con las personas integrantes de los círculos sociales, pues 9 de cada 10 personas envían mensajes todos los días, sin importar la cantidad de mensajes.

En lo referente a la segunda pregunta, las repuestas obtenidas fueron:

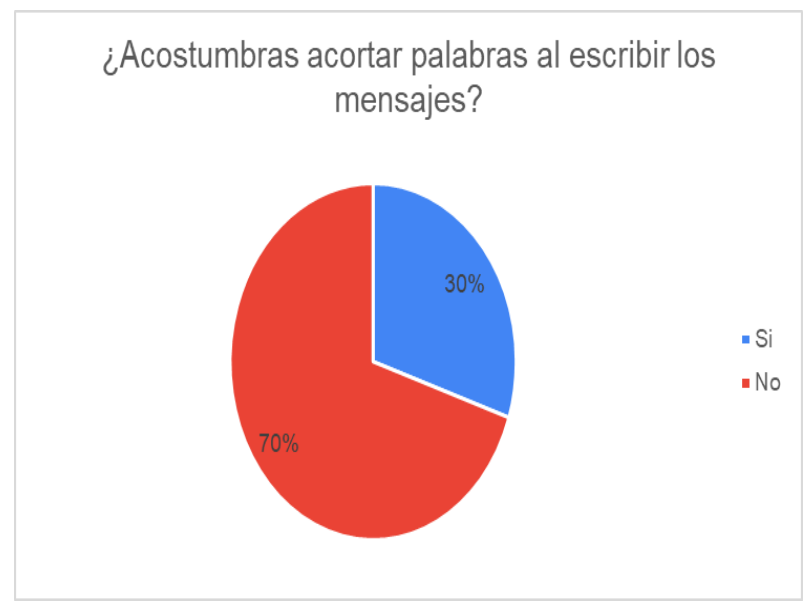

Gráfico 2 ¿Acostumbras acortar palabras al escribir los mensajes?

Fuente: Elaboración propia

Aunque la mayoría de los encuestados afirman que no recortan palabras al escribir, 3 de cada 10 personas si realiza esta práctica, lo cual es un indicativo de cierta tendencia actual hacia la deformación del mensaje, pues las palabras que se acortan generalmente no suelen ser las que cuentan con algún tipo de abreviatura.

La siguiente pregunta, la número 3, buscaba indagar sobre las palabras más comunes que acortan las personas, encontrándose una variedad muy amplia de respuestas, siendo las palabras más recurrentes que suelen ser recortadas las siguientes: Xq, Vdd, Ntp, Sta, Dnd, Cndo, St, Bn, Tqm, Alv, Vlv, X, Tons, Cmo, Acs, Mms, ey, cel, ontas, ola, dbsn, k, salu2, k onda, msj, ptm, tmb, ntc, thx, info, xfa, $\mathrm{bb}, \mathrm{X} 2$; varios de los recortes que se hacen incluyen cambios de letras o faltas de ortografía, además de referirse a groserías o palabras altisonantes.

En la pregunta 4 se indaga sobre las palabras que cada persona identifica que otras personas acortan en sus textos o mensajes; en esta pregunta también se encontraron respuestas muy variadas, resumiéndose en las siguientes, las cuales presentan una mayor frecuencia: Xq, Bn, Inf, Tkm, Tqm, Ntc, bb, Dnd, Xfa, Ntp, Cdt, $\mathrm{K}$, Hbd, Kmo, Hcs, Alv, Msj, Tgp, Txt, Bb, Tmb, Grx, Smn, Ola, X2, Amix, Bno, Ksa, Vdd, Maso; al igual que en la pregunta 3 , se pueden encontrar recortes que incluyen cambios de letras o faltas de ortografía, así como groserías. 
En seguida, a través de la pregunta ¿Cuál es la razón por la que comúnmente se acortan las palabras?, se buscaba establecer las razones de esta práctica, considerando como principales motivos el tiempo, el espacio de los mensaje o cuestiones personales; las respuestas se resumen en la siguiente gráfica:

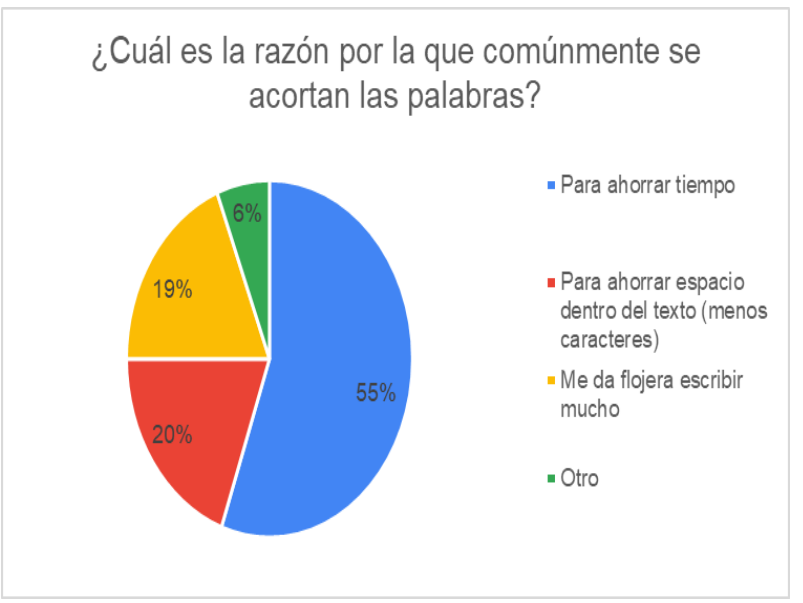

Gráfico 3 ¿Cuál es la razón por la que comúnmente se acortan las palabras?

Fuente: Elaboración propia

La principal justificación para acortar palabras en el ahorro de tiempo, seguido por el ahorro de espacio, acumulando entre ambas respuestas al $75 \%$ de los encuestados.

La pregunta seis muestra información acerca de si las personas se dan cuenta si saben o no la forma correcta de escribir alguna palabra, encontrándose que una mayoría abrumadora ( $94 \%$ de los encuestados), si tiene consciencia de saber o no como la forma correcta, tal y como se muestra en la siguiente gráfica.

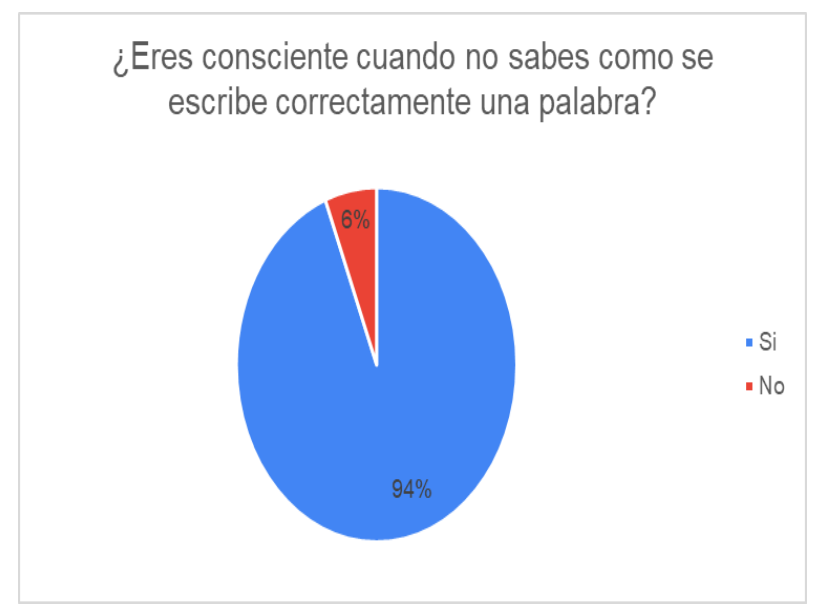

Gráfico 4 ¿Eres consciente cuando no sabes cómo se escribe correctamente una palabra?

Fuente: Elaboración propia
La séptima pregunta de la encuesta buscaba obtener información sobre el interés de las personas en conocer y usar la forma correcta de escritura de una palabra. En ella se encontró que el $92 \%$ de las personas trataba de averiguar la forma correcta de escritura de una palabra, ya se investigando bien preguntando.

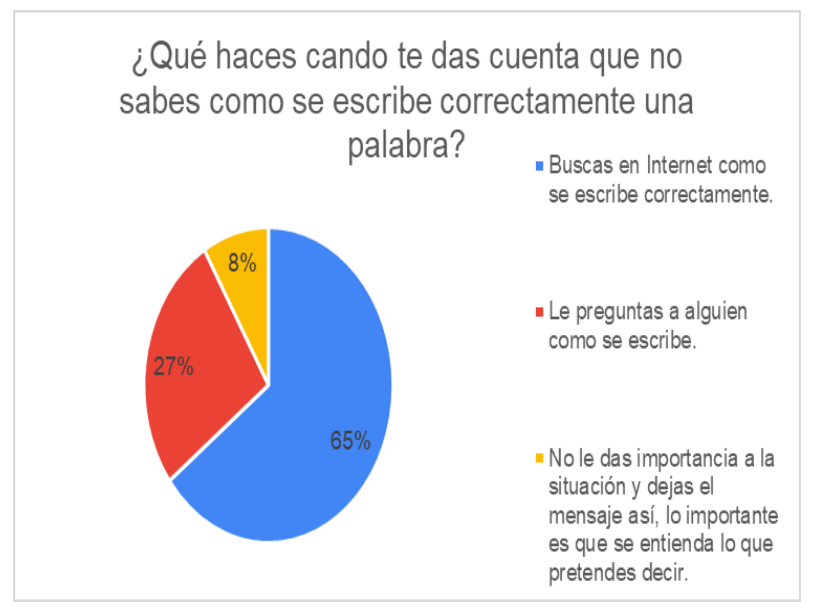

Gráfico 5 ¿Qué haces cuando te das cuenta que no sabes cómo se escribe correctamente una palabra?

Fuente: Elaboración propia

Un motivo por el que se deforma el lenguaje es por la moda. La pregunta 8 indaga sobre esta posibilidad, preguntando a los encuestados sobre si han seguido modas en la escritura de alguna palabra. En ella se encontró que 2 de cada 3 encuestados aseguran no hacerlo.

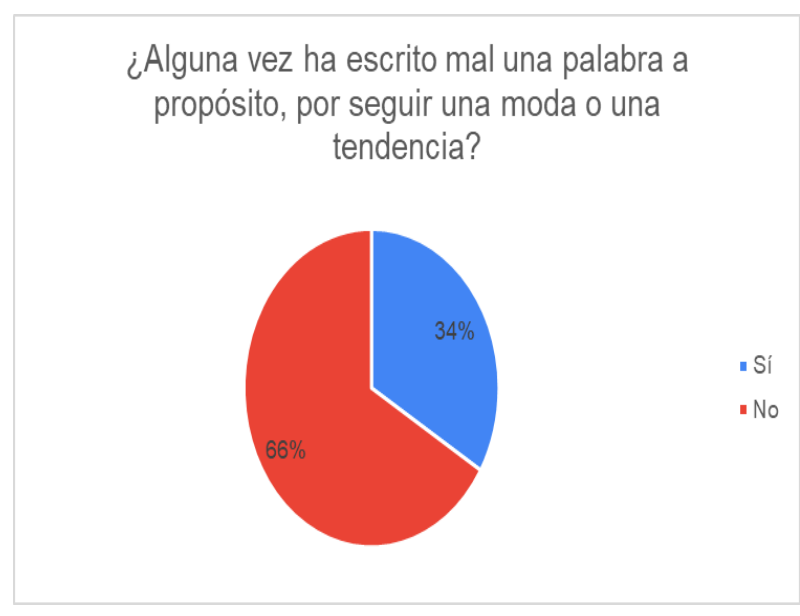

Gráfico 6 ¿Alguna vez $\mathrm{h}$ escrito mal una palabra a propósito, por seguir na moda o una tendencia? Fuente: Elaboración propia 
Una vez sabiendo cuantas personas escriben mal alguna palabra de forma intencional, en la pregunta 9 se pidió que hicieran un listado sobre cuáles palabras eran las que escribían de forma errónea por moda o tendencia; las respuestas a esta pregunta fueron muy variadas, siendo las más frecuentes las enumeradas a continuación: Ases, Hacer, Acs, Grax, Kiero, Alv, Ke, Bro, Bb, Tqm, Kuando, Keria, Zer, Okay, Olovorgo, Obvi, Sip, Nop, Chi, Weno, Ogt, Loka, Nse, Grax, 100pre, Kyc, Musho, Nta, Bai, Boy, Ise, Aiga, Jalowin, Amix, Ontas, Mimir, Hdspm, Gueno, Khe. Como se puede observar en el listado de preguntas, estas incluyen "abreviaciones" y groserías.

De igual forma, en la pregunta 10 se solicitó que se enumerarán palabras mal escritas que han observado que otras personas usan por seguir una moda. Las principales respuestas fueron las siguientes: Ola, Q, Ace, Xfa, Ayuwoki, Xq, Tkm, Feis, Grax, Komo, Amiwa, Ksa, Prro, Ptm, Amix, Holi, y todas las de la lista de respuestas de la pregunta 9.

Ahora bien, una tendencia recurrente en los mensajes escritos es el uso indiscriminado de imágenes. La pregunta 11 de la encuesta busca establecer las razones del por qué se utilizan tantas imágenes en lugar de utilizar palabras. Lo que se encontró fue que el $68 \%$ de los encuestados considera que las imágenes ayudan a expresar mejor lo que se quiere o se siente.

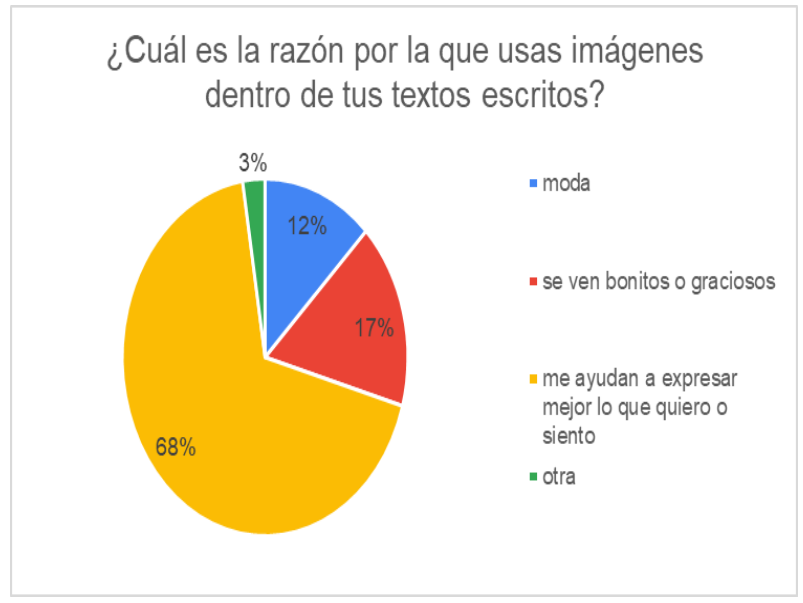

Gráfico 7 ¿Cuál es la razón por la que usas imágenes dentro de tus textos escritos?

Fuente: Elaboración propia
Las opciones que brindan tanto las utilidades de mensajería como los mensajes multimedia y las distintas redes sociales, en lo concerniente a la inclusión de imágenes en los mensajes de texto son amplias; la pregunta 12 recopila información sobre los tipos de imágenes que se utilizan en estos medios; las respuestas obtenidas señalan que prácticamente 2 de cada 3 personas utilizan principalmente los emojis como opción de imagen en sus mensajes.

¿Cuál de las siguientes imágenes utilizas con mayor frecuencia para comunicarte en tus redes sociales?

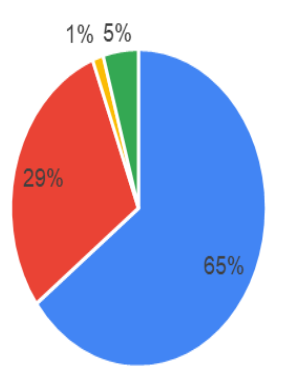

Gráfico 8 ¿Cuál de las siguientes imágenes utilizas con mayor frecuencia para comunicarte en tus redes sociales? Fuente: Elaboración propia

La globalización presente en este momento histórico ha provocado que, al menos en nuestra sociedad, se presente cada vez un mayor uso de palabras de otros idiomas (extranjerismos) en la forma coloquial de comunicación; esto a llegado a convertirse en una constante en los mensajes escritos. La pregunta 13 muestra como resultados que el $63 \%$ de los encuestados hace uso frecuente de palabras de otro idioma en su comunicación.
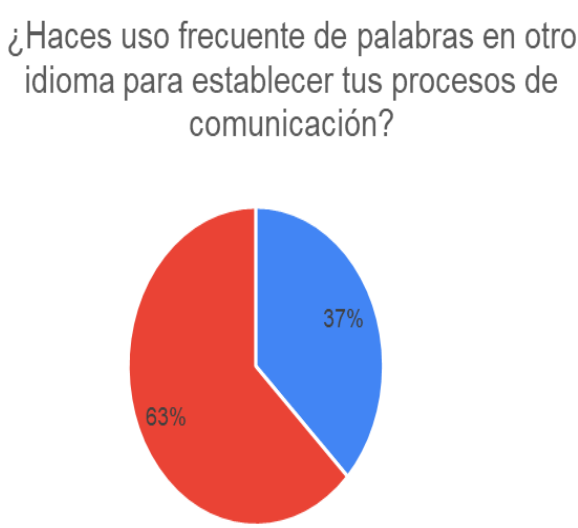

Gráfico 9 ¿Haces uso frecuente de palabras en otro idioma para establecer tus procesos de comunicación?

Fuente: Elaboración propia 
Teniendo claro que un amplio porcentaje de los encuestados usan palabras de otros idiomas, la siguiente pregunta recaba información sobre que palabras son las más usadas, obteniendo, como principales respuestas las siguientes: What, Ok, Mood, Crush, Sad, Love, Brother, Bye, Hello, Nice, Yes, Sorry, Party, Thanks, Please, Friend, Fake, Cool, Baby, But, When, Maybe, Please, Sister, Mother, Beer, Good, House, Why, Hi, Like, Worry, Good morning, Boyfriend, Nice, Men, Man, Woman, Miss you, Loser, Fuck, Damn, Crush, Daddy, Inbox

Finalmente, la última pregunta de la encuesta indaga en la creencia de las personas en la influencia de las redes sociales en su capacidad de comunicarse con otras personas. Como resultado dela pregunta, se encontró que el $87 \%$ de los encuestados considera que las redes sociales si influye en su capacidad de comunicación.

\section{$¿$ Consideras que el uso de las redes} sociales influye en tu capacidad de comunicarte con otros?

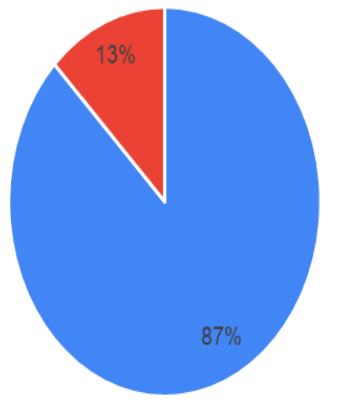

Gráfico 10 ¿Consideras que el uso de las redes sociales influye en tu capacidad de comunicarte con otros? Fuente: Elaboración propia

\section{Conclusiones}

El lenguaje en su relación directa con los procesos comunicativos en la transformación del ser humano con el paso del tiempo, se ha visto afectado gracias a diferentes factores, sociales y culturales, que van modificando su uso por las necesidades propias de la población. Con la adaptación de las diferentes herramientas tecnológicas, así como la apertura a un mundo de posibilidades que ha generado el proceso de globalización y el acercamiento a cualquier cultura, que ha posibilitado el uso del internet.
Un lenguaje asertivo, sin embargo, siempre será una necesidad real, para los procesos de comunicación efectivos, en la correcta relación entre las personas. La deformación de éste, por ende, trae como consecuencia, problemas en el entendimiento entre las masas, ocasionando conflictos de diferente índole.

En la preparación académica profesional, es de vital importancia, la preocupación por asegurar, que los futuros profesionales sean capaces de desarrollar procesos comunicativos asertivos, y que su capacidad de usar el lenguaje correctamente esté garantizada. Sin embargo, en cada generación, los alumnos ingresan con deficiencias mayores en su desarrollo verbal, tanto en la expresión oral como escrita, por lo que analizar las causas en la deformación del uso de su lenguaje se consideró vital, para la generación posterior de posibles estrategias de acción, para corregir los daños que se han ocasionado en la estructura básica del lenguaje.

Se concluye pues, que el uso de la tecnología ha afectado negativamente a la población en relación a la falta de empeño en el cuidado de los signos ortográficos y la estructura sintáctica, generando una despreocupación por la forma y ocupándose solamente de las ideas base.

El uso de imágenes como signos de comunicación ha crecido considerablemente, en la necesidad de expresar sentimientos en los procesos de comunicación indirecta, por lo cual, se está reduciendo el uso de la palabra, en un proceso de comunicación escrita, olvidando a su vez, el uso de signos de puntuación creados en un principio para la expresión de emociones.

La correcta ortografía ha pasado a segundo plano, los teléfonos inteligentes, han sustituido la capacidad cognitiva a través de la cual se analiza la forma correcta de la escritura de una palabra, los usuarios solo se preocupan por la expresión y dejan a la tecnología, la tarea de corregir lo incorrecto. 
Por último, la inclusión de otros idiomas, entre las necesidades básicas del desarrollo personal y profesional, en conjunto con la globalización, han ido reduciendo la importancia en la identidad del lenguaje propio, adaptando a éste extranjerismos, que incluso éstos son modificados, lo que ocasiona la generación de conceptos nuevos en una estructura disfuncional.

El camino por recorrer es largo, las deformaciones generadas en la estructura del lenguaje y las influencias que lo ocasionan, muy diversas. Pero estas mismas influencias, pueden servir como referente para la investigación de futuras estrategias de acción para la corrección de las diferentes problemáticas generadas.

\section{Referencias}

DNA, (2011). Escritura y deformación del lenguaje en redes sociales y otros medios de comunicación. El empresario mx. Recuperado de: http://elempresario.mx/redessociales/escritura-deformacion-lenguaje-redessociales-otros-medios-comunicacion.

Ducrot, O. \& Todorov, T. (2005). Diccionario enciclopédico de las ciencias del lenguaje. México: Siglo XXI Editores. 23 ${ }^{\mathrm{a}}$ ED. ISBN: 9789682317491

ENDUTIH (2019). Encuesta Nacional sobre Disponibilidad y Uso de Tecnologías de la Información en los Hogares. INEGI. Recuperado de: https://www.inegi.org.mx/contenidos/saladepre nsa/boletines/2020/OtrTemEcon/ENDUTIH_20 19.pdf

Lanier, J. (2018). Diez razones para borrar tus redes sociales de inmediato. USA: Editorial Picador USA. ISBN-13: 978-1250239082

Tello, M. (2019). El GIF animado como lenguaje visual en las conversaciones de chat.

Ticona, J. M. (2017). El facebook y la deformación del lenguaje escrito en los alumnos de la Facultad de Enfermería de la Universidad Nacional Federico Villarreal. Lima: UNIVERSIDAD NACIONAL DE EDUCACIÓN Enrique Guzmán y Valle Alma Máter del Magisterio Nacional ESCUELA DE POSGRADO. 